\title{
Copper-Catalyzed Alkyne-Azide Cycloaddition by Kinetic Resolution
}

\section{Key words}

copper catalysis

alkynes

azides

cycloaddition

kinetic resolution

\section{Synfact
of the} Month

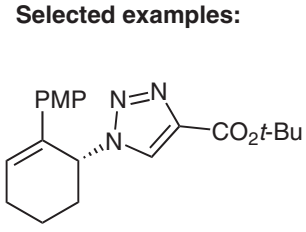

$95 \%$ yield, er > 99:<smiles>C/C=C(/c1ccccc1)[C@H](C)n1cc(C(=O)OC(C)(C)C)nn1</smiles>

$92 \%$ yield, er $=86: 14$ $E / Z=93: 7$<smiles>Oc1cn(C2CCCC=C2[18OH])nn1</smiles>

$80 \%$ yield, er $=97: 3$

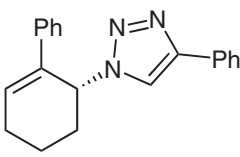

$85 \%$ yield, er $=96: 4$

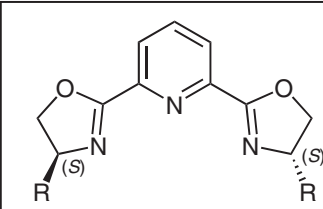

$(S, S)-4-\mathrm{Cl}-\mathrm{Ph}-\mathrm{PYBOX}$ ( $\mathrm{R}=4-\mathrm{Cl}-\mathrm{Ph}$ )

Match/mismatch experiment:

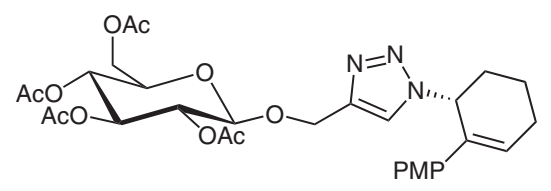

$99 \%$ yield, er $=93: 7$

Significance: Liu and Topczewski report a copper-catalyzed alkyne-azide cycloaddition by dynamic kinetic resolution (DKR) leading to $\alpha$-chiral triazoles in high yields. Due to the broad scope and the extension to complex fragments, this method should be of great interest for organic synthesis.
Comment: Interestingly, the diastereoselectivity was reversed by changing the stereochemistry of the ligand, showing the utility of this method. As an extension, derivatives of vitamin $\mathrm{E}$, gibberellic acid, esterone, glucose, mycophenolate mofetil and moexipril were successfully functionalized. 